\title{
Por uma abordagem enunciativa da tradução
}

\author{
Paula Ávila Nunes ${ }^{1}$
}

\begin{abstract}
Resumo: O trabalho tem por objetivo responder essencialmente duas perguntas: (1) como a Lingüística tem se relacionado com os estudos da tradução? e (2) qual o lugar que a Lingüística da Enunciação reserva para tradução? A primeira surge da constatação de que os estudos sobre tradução parecem ter se desenvolvido à margem da Lingüística, constituindo um campo de saber próprio. A proposta é, então, de pensar qual o lugar do fenômeno da tradução para as teorias lingüísticas contemporâneas, mais especificamente para a Lingüística da Enunciação, o que leva à segunda pergunta. Através dela, tenta-se evidenciar de que forma o campo dos estudos enunciativos da linguagem apresenta um arcabouço teórico favorável à abordagem da tradução.
\end{abstract}

Palavras-chave: tradução; crítica; Lingüística; Enunciação.

Há quase 50 anos, Georges Mounin, em seu Os problemas teóricos da tradução, dedicou mais de 200 páginas à defesa de que a tradução pode (e deve) ser um dos objetos de estudo da Lingüística. Passado quase meio século, a argumentação de Mounin - baseada no fato de que, segundo ele, a Lingüística parece se desviar da tradução como objeto de estudo - poderia parecer sem fundamento, se não fosse uma questão intrigante: grande parte dos trabalhos realizados no campo do que se convencionou chamar de Estudos da Tradução é produzida ora por tradutores, na busca de reflexão sobre sua prática profissional, ora por teóricos da literatura, ora por teóricos de outras áreas do conhecimento, mas poucos são os lingüistas que tomam como objeto de estudo o fenômeno da tradução, ainda que este seja, evidentemente, um fenômeno lingüístico. Se tal afirmação parece absurda, é só lembrarmos que o rol de pensadores ${ }^{2}$ que propuseram reflexões importantes sobre tradução é composto por filósofos ${ }^{3}$ (desde Cícero, talvez o primeiro pensador sobre tradução de que se tem notícia, passando por W. Von Humboldt, Walter Benjamin, Jacques Derrida), por escritores/ poetas (como Goethe, Friedrich Hölderlin, Friedrich Schleiermacher), críticos literários/ teóricos da Literatura (como John Dryden, Ezra Pound, George Steiner, Gideon Toury,

1 Doutoranda em Letras pela Universidade Federal do Rio Grande do Sul

2 Os nomes aqui listados foram selecionados com base em alguns compêndios sobre tradução (Baker, 2004; Gentzler, 2009; Milton, 1998; Munday, 2009; Venuti, 2004), que os citam por suas contribuições para o campo.

3 A classificação que proponho aqui é meramente didática, pois, sabemos, vários dos autores citados dedicaramse a diversas áreas do conhecimento, não sendo apenas escritores, ou críticos literários, por exemplo. 


\section{Conexão Letras}

e, mais recentemente, André Lefevère, Susan Bassnett, Rosemary Arrojo) e tradutores profissionais (como Antoine Berman e Lawrence Venuti). Do lado dos lingüistas, a lista é bem menos extensa, tendo em Eugene Nida, Roman Jakobson e John Catford os nomes mais importantes, sobretudo com seus trabalhos sobre equivalência ${ }^{4}$.

Esse breve recordatório permite entender porque os Estudos da Tradução, sobretudo em suas teorias mais recentes (pós-década de 60) se afastaram de uma abordagem lingüística (cf. Riccardi, 2002; Munday, 2008), passando a levar em consideração o fenômeno tradutório por outros prismas, tais como o cultural, o antropológico, o literário, etc. E tal postura advém do fato de que, para muitos teóricos da tradução, a Lingüística é insuficiente para abordar este objeto teórico, dado que as pesquisas orientadas por este viés parecem possuir uma "obsessão pela idéia de equivalência per se e com a equilavência em níveis lingüísticos, o que é considerado muito pouco para ser de significância central para os esforços do tradutor"5 (Malmkjaer, 2002: 111) ${ }^{6}$. A própria afirmação de que uma abordagem lingüística deu lugar a abordagens culturais, antropológicas, literárias, etc é sintomática do pensamento de que a Lingüística exclui de sua análise tais variáveis, como se os aspectos culturais, antropológicos e literários não tivessem lugar em uma análise lingüística.

Nessa conjuntura, é perfeitamente justificável que, tal como alguns autores defendem, os Estudos Tradutórios reclamem por uma espécie de "emancipação" da Lingüística; isto é, se o senso comum poderia nos fazer afirmar que os Estudos de Tradução formam uma sub-área da Lingüística, os teóricos da tradução a defendem como uma disciplina autônoma, ou melhor, uma interdisciplina, na medida em que "toma elementos de disciplinas vizinhas: não apenas a Lingüística e a Literatura Comparada, mas também os estudos culturais, a filosofia, a antropologia, a psicologia, a etnografia, a sociologia, os estudos comunicacionais, a semiótica e os estudos sobre mídia, para citar os mais proeminentes"77 (Ulrych e Bosinelli, 1999:236, citado em Riccardi, 2002:2 - grifos meus). É o caso, por exemplo, de Antoine Berman (2007:18), enfático em seu pensamento de que a

tradução não é nem sub-literatura (como acreditava-se no século XVI), nem uma sub-crítica (como acreditava-se no século XIX). Também não é uma lingüística ou uma poética aplicadas (como acredita-se no século XX). A tradução é sujeito e objeto de um saber próprio.

Tal visão já é, inclusive, adotada pelo autor desde a publicação de seu livro L'épreuve de l'étranger, datado de $1984^{8}$. Nele, Berman defende:

\footnotetext{
4 No Brasil, especificamente, o cenário parece mais balanceado: se, por um lado, alguns de nossos maiores teóricos sobre tradução, como Haroldo e Augusto de Campos, John Milton são escritores e/ou críticos literários, temos, por outro lado, uma sólida abordagem da tradução feita por lingüistas como Paulo Ottoni e Francis Aubert.

5 Todas as citações contidas neste texto, quando não escritas originalmente em português, foram traduzidas por mim. A versão original poderá ser consultada em nota de rodapé.

6 No original: "obsession with the idea of equivalence per se and with equivalence at linguistic levels which are deemed too low to be of central significance to the translator's endeavors".

7 No original: “(...) drawing on elements from neighboring disciplines: not only linguistics and comparative literature, but also cultural studies, philosophy, anthropology, psychology, ethnography, sociology, communication studies, semiotics and media studies, to name the most prominent".

8 Essa informação é interessante pois os Estudos de Tradução receberam esse nome (em inglês, Translation Studies) e se estabeleceram, oficialmente, como disciplina apenas quatro anos depois, em 1988, quando o artigo de Holmes, originalmente datado de 1972, se torna amplamente divulgado (cf. Munday, 2001). É neste mesmo ano que Snell-Hornby, na primeira edição de seu Translation Studies: an integrated approach, propõe que a área seja vista como disciplina independente. Berman, no entanto, já defendia tal hipótese antes dos dois autores, o que mostra que o sentimento de independência do campo data de ainda mais tempo.
} 
(...) deve-se afirmar que a tradução não pode jamais constituir uma simples ramificação da lingüística, da filologia, da crítica (como acreditavam os românticos) ou da hermenêutica: ela constitui - quer se trate de filosofia, de religião, de literatura, de poesia, etc. - uma dimensão sui generis. E produtora de um certo saber ${ }^{9}$. (p. 286 - grifos do autor).

Por outro lado, como o mesmo Berman lembra, mesmo este saber próprio pode sofrer influências e até ser transformado por outras experiências, outras práticas e outros saberes. É com relação a este último que afirma que "é claro que a Lingüística, no século XX, pode enriquecer a consciência sobre tradução; o inverso, a propósito, é igualmente verdadeiro" (1984:286). Também é inquestionável que, por se tratar de um ato de linguagem (cf. Meschonnic, 1999; Ottoni, 2005a), a tradução mereça uma abordagem lingüística, uma vez que "a prática generalizada da comunicação interlingual, em particular as atividades de tradução, devem ser objeto de atenção constante da ciência lingüística" (Jakobson, 2003:66).

É em meio a essa "questão identitária" e epistemológica que qualquer estudo lingüístico sobre tradução emerge hoje, e propus retomá-la pois, para um lingüista, parece ter se tornado necessário justificar seu interesse pela atividade tradutória. No entanto, este texto não pretende discutir a pertinência ou não dos Estudos da Tradução à Lingüística, ainda que parta desta discussão, pois, independentemente da posição adotada, duas constatações são incontestáveis: (1) a tradução é um fenômeno lingüístico; (2) a Lingüística é a ciência que trata de fenômenos lingüísticos. Tendo isto em vista, meu objetivo é o de justificar uma abordagem enunciativa da tradução, o que, acredito, distingue-se das abordagens lingüísticas comumente desenvolvidas, por não se ater apenas ao nível lingüístico, ainda que não prescinda - e até mesmo parta - dele. Isso porque um estudo enunciativo da tradução não se atém apenas a questões de equivalência (e menos ainda à equivalência no âmbito estritamente lingüístico, como tanto criticam os teóricos da tradução), mas desenvolve-se levando em consideração inúmeros outros fatores (tais como forma, sentido, e, principalmente, subjetividade) que adquirem relevância para se pensar tradução.

Tento ilustrar, portanto, que uma abordagem lingüística da tradução é possível, sem reduzi-la a um fenômeno de língua, mas pensando-a como um fenômeno de linguagem (oposição explicada mais adiante), com todas as implicações que isso gera. Para tanto, tomo, como ponto de partida, as considerações de Ottoni (op. cit), para quem "a lingüística não dá conta da tradução enquanto um acontecimento que emerge do funcionamento da linguagem" (p. 23), reconstituindo a linha de raciocínio que leva o autor a tal afirmação, para, posteriormente, argumentar em favor de uma abordagem enunciativa da tradução que leve em conta esse funcionamento.

\section{A crítica à Linguística Estruturalista}

Em seu artigo $O$ papel da Lingüistica e a relação teoria e prática no ensino da tradução ${ }^{10}$, Paulo Ottoni defende a idéia, já antecipada acima, de que o arcabouço teórico da Lingüística não é suficiente para abordar a complexidade do fenômeno tradutório. Com

9 No original: (...) il faut affirmer que la traduction ne peut jamais constituer une simple branche de la linguistique, de la philologie, de la critique (comme le croyaient les Romantiques) ou l'herméneutique: elle constitue - qu'il s'agisse de philosophie, de religion, de littérature, de poésie, etc. - une dimension sui generis. Et productrice d'un certain savoir.

10 O artigo é datado de 1996, e integra o livro Tradução manifesta (cf. bibliografia). 


\section{Conexão Letras}

relação a isso, é importante lembrar, logo de início, que a Lingüística a que se refere o autor é aquela rotulada como Estruturalista, que, em seu artigo, se equaciona à Lingüística desenvolvida a partir do Curso de Lingüistica Geral. Em oposição a ela, seu texto defende que a Lingüística que se convencionou chamar de Pós-estruturalista é a única capaz de abordar a tradução como fenômeno de linguagem (em oposição a um fenômeno de língua, que não considera a fala, ou seja, o uso individual), o que ele argumenta ser o caso da Teoria da Desconstrução, de Jacques Derrida. Por esta ótica, por ser a Enunciação uma Lingüística diretamente ligada ao pensamento saussuriano (cf. Flores e Teixeira, 2005; Flores e Nunes, 2007), e sendo, portanto, passível de ser considerada como pertencente ao grupo das "teorias pós-estuturalistas", parece lícito afirmar que, tanto quanto a Teoria da Desconstrução, a abordagem enunciativa também dispõe de aparato teórico-metodológico para abordar a tradução como fenômeno de linguagem. Antes de defender essa hipótese, porém, é necessário entender os motivos que levam Ottoni a tais considerações.

\subsection{A divisão língua-linguagem, sujeito-objeto}

$\mathrm{O}$ autor parte da concepção de que, para fundar a Lingüística, Saussure ${ }^{11}$ viu-se obrigado a distinguir língua e linguagem, uma vez que a última, por seu caráter heteróclito e sua falta de unidade interna, não poderia ser objeto de uma ciência ${ }^{12}$. Isso implica que, por ser a língua a linguagem menos a fala, o objeto da Lingüística teria excluído a liberdade individual de uso da língua, ou, mais precisamente, teria excluído o sujeito de seu escopo. E isso traz uma conseqüência profunda para o modo de pensamento que se instaura a partir da fundação da Lingüística: excluir o sujeito do escopo teórico equivale a endossar a dicotomia sujeito-objeto o que, em última análise, implicaria uma cisão entre teoria e prática:

A crença na dicotomia teoria $x$ prática, sobre a qual tem se baseado todo o arcabouço do conhecimento ocidental, traz pelo menos duas conseqüências: 1. A possibilidade de uma oposição clara e objetiva entre teoria e prática emerge da crença na possibilidade da oposição entre sujeito e objeto, em que o primeiro pretende não apenas descrever e controlar o segundo, mas também não misturar-se com ele. A possibilidade dessa oposição necessariamente anula a subjetividade do sujeito em relação com o objeto (...) (Arrojo, 2003:108) $)^{13}$.

Transportando esta hipótese de cisão entre sujeito-objeto para o campo dos estudos da tradução, a implicação é imediata: se a Lingüística, para se constituir, precisou abrir mão da figura do sujeito, tomando seu objeto, como diz Arrojo, desprovido de subjetividade, "podemos afirmar que, teoricamente, a tradução é absolutamente possível para a lingüística,

11 Emprego o nome de Saussure, neste caso, por fidelidade ao texto de Ottoni, uma vez que, dadas as descobertas dos manuscritos originais do genebrino e toda a reflexão teórica que deles advêm, é insustentável afirmar que Saussure estabelece uma ou outra coisa. A terminologia apropriada seria que o Curso de Lingüistica Geral, tal como foi concebido, estabelece tais considerações. Este texto não endereça a problemática de que o $C L G$ não é resumitivo do pensamento de Saussure e nem de como as reflexões dos manuscritos poderiam pôr em xeque as idéias de Ottoni, pois, tal como afirma Normand (2007), se outras visões sobre o pensamento de Saussure se tornaram possíveis com a descoberta dos manuscritos, eles não invalidam a leitura do próprio Curso. Além disso, a interpretação de Ottoni é exemplar da forma como o livro é freqüentemente lido por muitos lingüistas, com certas imprecisões não respaldadas por uma leitura atenta do Curso. Mesmo assim, seu raciocínio, ainda que parte de uma leitura questionável do $C L G$, propõe algumas considerações que são de interesse para este trabalho, motivo pelo qual recorro às considerações do autor.

12 Obviamente, toma-se aqui uma visão positivista de ciência; "logocêntrica", nos termos de Ottoni.

13 Este trecho é citado por Ottoni à página 22. 
mas sem a interferência de um tradutor" (p. 28) ${ }^{14}$. Isso porque, ainda segundo a visão de Ottoni, ao tomar a língua como sistema de signos, em que significado e significante estão em perfeita oposição, ela se torna "um todo por si" (Saussure, 2005:17), ou seja, um todo estável, que não depende do sujeito e do uso que ele faz da língua ${ }^{15}$. Por este viés, a Lingüística não conseguiria compreender o ato tradutório, pois parte "da postura do tradutor como um transportador de significados estáveis de um sistema - de uma língua - para outro, aquele que vai transportar significados entre dois sistemas fechados e diferentes entre si” (p. 27).

Considerando esse raciocínio, a tradução é possível, para a Lingüística, somente na teoria, enquanto que a "tradução é impossível se for encarada (...) na sua prática, na qual intervêm, inevitavelmente, caraterísticas individuais que contrariam a perfeita oposição entre significado e significante" (p. 29 - grifo do autor). Vê-se aí como a clivagem sujeitoobjeto ecoa em uma divisão entre teoria e prática e, em última instância, entre língua como sistema abstrato e o uso individual que cada falante faz dela.

No entanto, como sabemos, mesmo que apenas empiricamente, a tradução não acontece senão pela mobilização da língua (sistema abstrato) através de um uso individual. Assim, o processo tradutório não pode ser pensado desarticulado do sujeito tradutor, e isto por pelo menos um motivo: traduzir implica operar sobre significados, sobre sentidos, e "é só o indivíduo-tradutor que tem condições de produzir e transformar esses significados em outros, dentro do jogo de diferenças e semelhanças do sistema da língua" (p. 32). É sobre este ponto que podemos, então, pensar em uma abordagem enunciativa da tradução, uma vez que enunciar é precisamente "colocar a língua em uso por um ato individual de utilização" (Benveniste, 1989:82).

\section{Por uma abordagem enunciativa da tradução}

Do exposto até agora, podemos entender que a crítica a uma abordagem lingüística da tradução deriva do fato de que ela contempla o fenômeno tradutório através de uma perspectiva que o reduz a um fato de língua, isto é, desconsidera que há um sujeito que traduz e que esse sujeito faz escolhas, interpreta, produz sentidos. Tal visão está em oposição à consideração da tradução como um fato de linguagem, perspectiva que Ottoni defende ser o diferencial das teorias Pós-estruturalistas (mais especificamente, ou talvez até exclusivamente, a Desconstrução proposta por Jaques Derrida). Talvez seja exatamente por essa exclusão da subjetividade implicada na tradução que a abordagem lingüística tenha perdido seu espaço para os estudos funcionalistas e culturais, a partir da década de 60, bem como, mais recentemente, para uma abordagem literária (cf. Riccardi, 2002a).

No entanto, se, como propõe Ottoni, a Lingüística Pós-estruturalista pode ser vista como uma "nova postura epistemológica" (p. 27), capaz de contemplar a tradução como uma manifestação lingüística que põe "a linguagem em funcionamento na sua totalidade" (p. 25), a Lingüística da Enunciação, em suas diferentes teorias, passa a ser uma possível escolha teórica para abordagem desse fenômeno. Isso porque, se minha leitura do texto de Ottoni estiver correta, suas críticas levam-nos a inferir alguns "requisitos" necessários para que a Lingüística possa abordar a tradução, e a Enunciação parece estar alinhada

14 Todas as citações desta sessão, salvo quando indicado o contrário, provêm do texto de Ottoni, motivo pelo qual só apresento a página em que se encontram.

15 Este é um dos pontos em que me afasto da perspectiva de Ottoni. Ainda que a língua possa se configurar em um "todo por si", ela é dependente do sujeito, do falante, pois somente ele pode determinar o que é ou não língua. O sujeito tem, portanto, um papel fundamental na teoria saussuriana. 
com tais exigências. De forma resumitiva, os requisitos me parecem ser os seguintes: uma abordagem lingüística da tradução não pode

(1) abordar a linguagem fora de seu funcionamento;

(2) separar sujeito e objeto;

(3) ignorar a presença do tradutor como agente em todo o processo tradutório;

(4) pressupor que o tradutor seja um transpositor de sentidos únicos e estáveis de uma língua para outra; e

Minha proposta é, neste momento, verificar em que medida a Lingüística da Enunciação preenche tais expectativas, tendo por base a Teoria da Enunciação de base benvenistiana.

\subsection{A Lingüística da Enunciação aborda a linguagem em seu funcionamento}

Dentre as características que unificam o campo enunciativo de estudos da linguagem, está talvez a mais estruturante: toda a abordagem enunciativa propõe uma visão de língua observada a partir do ponto de vista do sentido. Por isso, costuma-se dizer que se trata de uma semântica da enunciação e, como nos ensina Benveniste, "a noção de semântica nos introduz no domínio da língua em emprego e em ação" (1989:229 - grifos meus). Desta forma, o uso se torna "um princípio de discriminação, um critério" (ib, p. 227), pois é somente "no uso da língua que um signo tem existência" (id.). O sentido, tal como considerado pelos enunciativistas, só emerge da linguagem em funcionamento, o que diferencia este ponto de vista teórico de uma abordagem imanentista, que considera a língua por si mesma, fechada em si mesma (a língua como sistema de signos de que fala Benveniste). Há, assim, uma "diferença profunda entre a linguagem como sistema de signos e a linguagem assumida como exercício pelo indivíduo" (Benveniste, 2005:281): para a Enunciação, o que existe é a linguagem enquanto manifestação lingüística necessariamente realizada por um sujeito que coloca a língua em funcionamento. É somente a partir deste funcionamento que se pode, então, tecer quaisquer considerações sobre a linguagem. Portanto, é conseqüência imediata que não haja separação entre sujeito e objeto, assunto do próximo item.

\subsection{A Lingüística da Enunciação não separa sujeito e objeto}

Se uma das grandes críticas que Ottoni faz à Lingüística estruturalista se sustenta no fato de ela separar sujeito e objeto, de forma a ignorar a subjetividade inerente a qualquer uso da língua, a Lingüística da Enunciação realiza exatamente o movimento contrário ao colocar a subjetividade no centro de sua análise, pois "a linguagem só é possível porque cada locutor se apresenta como sujeito, remetendo a ele mesmo como eu no seu discurso" (Benveniste, 2005:286 - grifos do autor). O fundamento da subjetividade encontra-se, pois, no exercício mesmo da língua, fazendo com que "a linguagem (...) [seja] a possibilidade da subjetividade" (ib, p. 289). Dado que "a enunciação supõe a conversão individual da língua em discurso" (Benveniste, 1989:83), toda a teoria enunciativa deve ser capaz de observar como, ao mobilizar o sistema da língua, o sujeito se marca naquilo que diz através de um uso lingüístico cujas características são sempre singulares. Dito de outra forma, o objetivo da análise repousa em "ver como o 'sentido' se forma em 'palavras"” (id.), o que caracteriza o processo de semantização da língua, sempre resultado singular da apropriação da língua por parte de um sujeito. Dessa forma, a Enunciação não só não separa sujeito e objeto como um não existe senão pelo outro: só há manifestação lingüística porque há, antes de tudo, um sujeito que enuncia. Isso leva ao ponto seguinte. 


\subsection{A Lingüística da Enunciação contempla a presença do tradutor na tradução}

Dado que a Enunciação se interessa pela subjetividade na linguagem, isto é, por como do locutor se passa ao sujeito (cf. Benveniste, 2005:286) - que se marca no que diz, deriva-se daí a constatação, um tanto óbvia, de que tanto tradução quanto tradutor são objetos de uma análise enunciativa. A Enunciação só concebe tradução enquanto um produto de um tradutor, e não como uma manifestação lingüística tomada per se. Isto é, não considera apenas o texto, o enunciado, ainda que parta dele, mas passa a

interrogar-lhe como produto de uma enunciação, resultado, portanto, de uma articulação particular de forma e sentido (cf. Benveniste, 1989), produzida pelo autor do original. Isso não quer dizer, no entanto, que o tradutor deve procurar saber $o$ que o autor quis dizer (se é que isso é possível sem uma explicação por parte do próprio autor); antes, o tradutor deve procurar saber como o autor disse o que disse, isso é, como o texto se configura em uma organização semântica particular, ou seja, como o texto produz sentido, como o autor, em seu uso particular da linguagem, articulou forma e sentido, produzindo uma sintaxe própria (Nunes, 2011, p.17-8).

Essa sintaxe própria em nada deve ser confundida com a sintaxe a que normalmente nos referimos nos compêncios gramaticais. Trata-se, na teoria benvenistiana, de uma relação específica de engendramento de forma e sentido, que ganha vida de duas formas: "por meio de índices específicos, de um lado, e procedimentos acessórios, de outro" (Benveniste, 1989:84). A primeira forma de o sujeito se marcar no que diz, aquilo que é chamado por Benveniste de índices especificos, está relacionada aos índices de ostentação, termo cunhado pelo autor para denominar os elementos lingüísticos que são "engendrados de novo cada vez que uma enunciação é produzida, e cada vez eles designam algo novo" (ib, p. 85). Constitui-se em um grupo finito de elementos, tais como os pronomes, tempos verbais, modalizadores, etc. Em uma visão estrita de estudo enunciativo, estes são precisamente os elementos que são observados, pois só existem na e pela enunciação.

No entanto, há aquilo que chamo de "uma segunda forma de o sujeito se marcar no que diz", constituída por um grupo infinito de possibilidades. É através dessa segunda forma que podemos pensar a relação, sempre singular, entre forma e sentido, o que nos leva, igualmente, a refletir sobre o que é o sentido para a Enunciação.

\subsection{A Lingüística da Enunciação não pressupõe sentidos estáveis e únicos}

Outra crítica feita por Ottoni à Lingüística Estruturalista diz respeito ao que ele chama de "sentido estável e único". Isso porque, segundo o seu raciocínio, uma vez que se exclua a subjetividade da linguagem, o que resta é a língua como sistema de signos e, conseqüentemente, como um sistema de oposições. Para o $C L G$, um signo não significa senão pela relação de oposição que mantém com os demais. O sentido se dá, portanto, pela negatividade e já é inerente ao sistema lingüístico. Benveniste, ao considerar a subjetividade o eixo central de uma análise enunciativa, depara-se com a questão: como o sujeito pode singularizar o que enuncia se há sentidos já antecipados pelo próprio sistema da língua? A resposta para esta problemática parece estar na sua concepção dos níveis semiótico e semântico de significação:

Coloco que há dois domínios ou duas modalidades de sentido, que distingo respectivamente como semiótico e semântico. O signo saussureano é na verdade a 
unidade semiótica, quer dizer, a unidade dotada de sentido. É reconhecido o que tem sentido; todas as palavras que são encontradas num texto francês, para quem domina esta língua, têm um sentido. Mas importa pouco que se saiba qual é este sentido e não se está preocupado com isso. O nível semiótico é isto: ser reconhecido como tendo ou não um sentido. Isto se define por sim, não. (...) A semântica é o "sentido" resultante do encadeamento, da apropriação pela circunstância e da adaptação dos diferentes signos entre eles. Isto é absolutamente imprevisível. É a abertura para o mundo. Enquanto que o semiótico é o sentido fechado sobre si mesmo e contido de algum modo em si mesmo (Benveniste, 1989:21).

Disso resulta que a semiótica "se caracteriza como uma propriedade da língua" (1989:230), enquanto que "a semântica resulta de uma atividade do locutor que coloca a língua em ação" (id.). A concepção de dois universos de sentido implica, fundamentalmente, uma mudança no próprio objeto de análise, que deixa de ser o signo e passa a ser a frase: "o signo semiótico existe em si, funda a realidade da língua, mas ele não encontra aplicações particulares; a frase, expressão do semântico, não é senão particular” (ib, p. 230 - grifo do autor).

Dado que a Enunciação aborda tanto o universo semiótico quanto o semântico, ainda que privilegie o último, é lícito afirmar que não se trata, portanto, da observação de sentidos estáveis e únicos, mas de sentidos evanescentes e produzidos, engendrados de forma nova cada vez que se enuncia.

\section{Considerações para um campo}

As considerações preliminares que desenvolvi aqui apontam para uma espécie de justificativa de uma abordagem lingüística da tradução que não se esgota no material lingüístico, como tanto criticam os estudiosos dos estudos tradutórios. No entanto, como ainda é necessário evidenciar através da revisão de como alguns teóricos do campo enunciativo tomaram a tradução como objeto de estudo, que mesmo dispondo de um arcabouço teórico favorável a uma abordagem do fenômeno tradutório, a Enunciação ainda permanece reticente a este objeto. Eis o primeiro motivo pelo qual um estudo enunciativo da tradução se torna convidativo.

Porém, acredito que a contribuição mais importante que uma análise enunciativa pode proporcionar esteja na contemplação do processo tradutório de forma bilateral. Se é verdade que a maioria dos lingüistas, conforme afirma Malmkjaer (op. cit.), se interessa pela tradução vendo sua relação com a Lingüística unilateralmente, isto é, pensando o que a Lingüística pode dizer sobre a tradução, minha proposta vai no sentido oposto. Ao mesmo tempo que, para um lingüista, é inevitável tomar a tradução como objeto de estudo, o processo não se esgota aí. É preciso também pensar o movimento contrário, indagando o que a tradução pode dizer à Lingüística. Isso porque, como lembra Meschonnic (op. cit.), "traduzir não se limita a ser o instrumento de comunicação e de informação de uma língua para outra" (p. 14); antes, "é o melhor ponto de observação sobre as estratégias de linguagem” (id.) ${ }^{16}$. É este ponto de observação privilegiado que pode nos ensinar um pouco mais sobre língua e linguagem, e, inevitavelmente, sobre sujeito, o que, indubitavelmente, interessa a todos nós, lingüistas do campo enunciativo.

16 Nos originais: « traduire ne se limite pas a être l'instrument de communication et d'information d'une langue à l'autre » e « c'est le meilleur poste d'observation sur les stratégies de langage » 
Referências

ARROJO, Rosemary (Org.). O signo desconstruído: implicações para a tradução, a leitura e o ensino. $2^{\mathrm{a}}$ ed. Campinas: Pontes, 2003.

BAKER, Mona (et al). Routledge encyclopedia of translation studies. $2^{\mathrm{a}}$ ed. Londres: Routledge, 2001.

BATALHA, Maria Cristina; PONTES JR., Geraldo. Tradução. Petrópolis: Vozes, 2007. BASSNETT, Susan. Translation Studies (new accents). Londres: Routledge, 2002.

BASSNETT, Susan; LEFEVERE, Andre. Where are we in translation studies? In: Constructing cultures: essays on literary translation. (Topics in Translation 11). Bristol: Multilingual Matters, 1998.

BENEDETTI, C.; SOBRAL, A. Conversas com tradutores: balanços e perspectivas da tradução. São Paulo: Parábola, 2003.

BENVENISTE, E. Problemas de lingüística geral I. Campinas: Pontes, 2005.

BENVENISTE, E. Problemas de lingüística geral II. Campinas: Pontes, 1989.

BERMAN, Antoine. L'épreuve de l'étranger: culture et traduction dans l'Allemagne romantique. Paris : Editions Gallimard, 1984.

. A tradução e a letra, ou, O albergue do longínquo. Rio de Janeiro: 7Letras/PGET, 2007. ECO, Umberto. Quase a mesma coisa. Rio de Janeiro : Record, 2007.

FLORES, Valdir do Nascimento; NUNES, Paula Ávila. Lingüística da enunciação: uma herança saussuriana? In: Organon (UFRGS), v. 21, p. 199-209, 2007.

FLORES, Valdir; TEIXEIRA, Marlene. Introdução à Lingüística da Enunciação. São Paulo: Contexto, 2005.

GENTZLER, Edwin. Teorias contemporâneas da tradução. São Paulo: Madras, 2009. JAKOBSON, Roman. Lingüística e comunicação. $19^{\circ}$ ed. São Paulo: Cultrix, 2003.

MALMJKJAER, Kirsten. Translation and linguistics: what does the future hold? In: Alessandra (Org.). Translation studies: perspectives on an emerging discipline. Cambridge: Cambridge University Press, 2002. p. 11-119.

MESCHONNIC, Henri. Poétique du traduire. Editions Verdier, 1999.

MILTON, John. Tradução: teoria e prática. $2^{a}$ ed. São Paulo: Martins Fontes, 1998. (Coleção leitura e crítica).

MOUNIN, Georges. Os problemas teóricos da tradução. São Paulo: Cultrix: 1975.

MUNDAY, Jeremy. Introducing translation studies: theories and applications. Londres: Routledge, 2001.

(Org.). The Routledge companion to Translation Studies. Londres: Routledge, 2009.

NORMAND, Claudine. Saussure: une épistémologie de la linguistique. Atas de Colóquio, Séoul, 2007.

NUNES, Paula Ávila. O tradutor como função enunciativa. Monografia de conclusão de curso. Porto Alegre: IL/UFRGS, 2008.

. Do bilíngüe ao tradutor, do enunciado à enunciação: notas sobre uma perspectiva enunciativa do tradutor e da tradução. Tradterm, nº18, 2011a. p. 09-27

OTTONI, Paulo. Tradução manifesta: double-bind \& acontecimento, seguido de Fidelidade a mais de um: merecer herdar onde a genealogia falta, de Jacques Derrida. Campinas: Editora da UINICAMP; São Paulo: EDUSP, 2005a.

(Org.). Tradução: a prática da diferença. $2^{\mathrm{a}}$ ed. Rev. Campinas: Editora da Unicamp, $2005 \mathrm{~b}$. RICCARDI, Alessandra. Introduction. In: RICCARDI, Alessandra (Org.). Translation studies: perspectives on an emerging discipline. Cambridge: Cambridge University Press, 2002a. 


\section{Conexão Letras}

. Translation and interpretation. In: RICCARDI, Alessandra (Org.). Translation studies: perspectives on an emerging discipline. Cambridge: Cambridge University Press, 2002b.

RODRIGUES, Cristina Carneiro. Tradução e diferença. São paulo: Editora UNESP, 2000.

SOBRAL, Adail. Dizer o "mesmo" a outros: ensaios sobre tradução. São Paulo: Special Book Services Livraria, 2008.

SAUSSURE, Ferdinand de. Curso de Lingüística Geral. São Paulo: Cultrix, 2005. SCHULTE, Rainer; BIGUENET, J. (Org.) Theories of translation: an anthology of essays from Dryden to Derrida. Chicago: The University of Chicago Press, 1992.

STEINER, G. After Babel: aspects of language and translation. Londres: Oxford University Press, 1998.

VENUTI, Lawrence. Escândalos da Tradução: por uma ética da diferença. Bauru: EDUSC, 2002. . (Org.) The translation studies reader. $2^{\mathrm{a}}$ edição. Londres: Routledge, 2004. 